\title{
SER PROFESSOR DE GEOGRAFIA: O QUE ME DIZ A SALA DE
}

\section{AULA}

\author{
Marcio Antonio Bezerra de Almeida Júnior, Universidade Federal de Campina Grande (UFCG) \\ marcioaldjr@gmail.com \\ Cícera Cecília Esmeraldo Alves, Universidade Federal de Campina Grande (UFCG) \\ ceciliaesmeraldo@gmail.com
}

\begin{abstract}
RESUMO
O estágio supervisionado é um componente curricular obrigatório para todos os discentes do Curso de Geografia, orientado pela Lei de diretrizes e bases da Educação nacional n ${ }^{\circ}$ 9394/96 nos cursos de formação de professores. O estágio supervisionado fortalece o componente teórico-prático como uma oportunidade de aprendizagem, permitindo ao discente uma percepção da realidade no âmbito escolar, momento esse de fundamental importância no processo da formação docente, pois o estágio supervisionado se caracteriza em uma atividade que possibilita ao discente uma oportunidade de colocar em prática todas as teorias aprendidas durante a sua formação acadêmica, aproximando os conhecimentos adquiridos durante a formação acadêmica com as práticas a serem desenvolvidas no processo ensino-aprendizagem no ambiente escolar da instituição em que vai estagiar. Este artigo tem como objetivo discutir a importância da teoria e da prática na formação de professores no Estágio Supervisionado em Geografia, realizando uma reflexão acerca do ensino de geografia e da necessidade do Estágio Supervisionado em Geografia para a formação docente, como meio de conhecer a realidade do âmbito escolar. Pesquisou-se e estudou-se bibliografias que possibilitassem o acesso a esse conhecimento, restringindo-se a experiência vivenciada durante o estágio supervisionado em Geografia. Os resultados obtidos com o estágio supervisionado foram positivos, pois evidenciou-se em uma oportunidade de ensino e aprendizagem, o que proporcionou o desenvolvimento de estratégias, saberes teóricos e práticos e competências profissionais necessárias para uma futura atuação profissional docente no mercado de trabalho, o estágio constituiu-se em um momento de ensinoaprendizagem, pesquisa e investigação do saber geográfico.
\end{abstract}

Palavras-chave: O ensino de geografia; estágio supervisionado; teoria e prática.

\section{ABSTRACT}

The supervised internship is a compulsory curricular component for all the students of the Geography Course, guided by the Law of guidelines and bases of the National Education $n^{\circ}$ 9394/96 in the courses of teacher training. The supervised stage strengthens the theoretical-practical component as a learning opportunity, allowing the student a perception of reality in the school environment, a moment of fundamental importance in the process of teacher training, since the supervised stage is characterized in an activity that enables the student An opportunity to put into practice all the theories learned during his / her academic training, bringing the knowledge acquired during the academic training closer to the practices to be developed in the teaching-learning process in the school environment of the institution in which he / she will work. This article aims to discuss the importance

Revista de Pesquisa Interdisciplinar, Cajazeiras, n. 2, suplementar, p.420-428, set. de 2017. 
of theory and practice in the training of teachers in the Supervised Internship in Geography, making a reflection on the teaching of geography and the need for supervised internship in geography for teacher training as a means of knowing reality of the school environment. We searched and studied bibliographies that allowed access to this knowledge, being restricted to the experience lived during the supervised stage in Geography. The results obtained with the supervised internship were positive, as evidenced in an opportunity of teaching and learning, which provided the development of strategies, theoretical and practical knowledge and professional skills necessary for a future professional work in the labor market, the Stage was constituted in a moment of teaching-learning, research and investigation of geographical knowledge.

Keywords: Geography teaching; supervised internship; theory and practice.

\section{INTRODUÇÃO}

O estágio supervisionado é um momento de fundamental importância no processo da formação docente, pois se configurando em uma atividade que possibilita ao discente a oportunidade de colocar em prática todas as teorias aprendidas durante a sua formação acadêmica. Aproximando os conhecimentos acadêmicos das práticas a serem desenvolvidas no processo ensino-aprendizagem.

O Estágio em geografia aproxima as teorias discutidas e aprendidas no processo de formação docente, colocando-as em prática, levando o discente a analisar situações e desenvolver habilidades como docente no ambiente escolar.

O estágio supervisionado fortalece o componente teórico-prático como uma oportunidade de aprendizagem, permitindo ao discente uma percepção da realidade escolar. Partindo de uma reflexão teórico-metodológica, este artigo tem como objetivo discutir a importância da teoria e da prática na formação de professores no Estágio Supervisionado em Geografia, realizando uma reflexão acerca do ensino de geografia e da necessidade do Estágio Supervisionado em Geografia para a formação docente, como meio de conhecer a realidade escolar.

Este trabalho está organizado da seguinte forma: Metodologia: Perspectivas de ensinar e ser professor de geografia: Inicialmente apresentam-se algumas considerações e reflexões com relação ao estágio supervisionado e, em seguida, análises do ensino de geografia numa perspectiva crítica-social, mediante a experiência vivenciada nos estágios; e finalmente, com as considerações em que o Estágio em Geografia propiciou para a futura atuação como docente. 


\section{METODOLOGIA}

Para o presente estudo, a turma observada durante o estágio foi o $2^{\circ}$ ano, turma A e B. O docente responsável pela turma foi Vanessa da Silva Santos. Graduada em Licenciatura em Geografia, pela Universidade Estadual da Paraíba (UEPB), é uma professora em contrato temporário com o Estado, e pretende seguir no magistério realizando posteriores mestrado e doutorado. Em seu perfil didático pedagógico, utiliza-se de uma metodologia tecnológica inovadora, como slides com imagens em PowerPoint, Retroprojetor, utilização de maquetes com materiais recicláveis para exposição em feira de ciências da Escola Estadual de Ensino Fundamental e Médio "Arruda Câmara”. Nota-se uma considerável satisfação por parte do aluno em relação a professora, que a mesma interage bem com os alunos, preocupando-se com o aprendizado dos mesmos.

A Escola Estadual de Ensino Fundamental e Médio "Arruda Câmara", dispõe de uma estrutura considerável. O colégio foi alvo recente reformas realizadas pelo governo do estado da Paraíba. O espaço das salas de aula é fisicamente bem estruturado, amplo e ventilado. A escola dispõe de sala de informática (com uma sala climatizada, estruturada com móveis resistentes, cadeiras confortáveis e computadores de última geração), laboratório de ciência, ginásio (recentemente construído), sala de vídeo (cadeiras e equipamentos recentes, muito utilizado pelos docentes) e auditório. A questão da acessibilidade foi planejada, a exemplo das rampas e estrutura de apoio aos portadores de necessidades especiais.

Em relação à disciplina Geografia, é notável o interesse relativo por parte dos alunos. É visível que nos alunos a capacidade de abstração com relação a certas ideias e contextos foi trabalhada, a exemplo de correlacionar mapas e texto. Durante as observações percebe-se: a disposição das carteiras, favorecendo a formação de grupos de dispersão; o interesse pelo assunto do livro didático (considerando a falta de acesso ao mesmo por alguns alunos), que é superado pela professora com o uso recursos didáticos extras. Todas essas questões foram obtidas durante a fase de observação das aulas e nas regências. Dentro desse aspecto tem-se que os livros didáticos desta série contemplam os interesses e a motivação por parte dos alunos. Sabendo desta condição foram elaborados resumos e esquemas no sentido de aumentar a participação assim como o entendimento coletivo dos conteúdos. 


\section{PERSPECTIVAS DE ENSINAR E SER PROFESSOR DE GEOGRAFIA}

O estágio supervisionado é uma exigência da Lei de diretrizes e bases da Educação nacional n 9394/96 nos cursos de formação de professores. Essa experiência no Estágio Supervisionado é de importância para a formação docente, pois oferece a oportunidade de integrar os acadêmicos com a área onde irá atuar e integrando a teoria e prática, para aplicá-la em sala de aula como futuro docente, tendo como base o conhecimento adquirido na vida acadêmica.

Pimenta e lima (2004), consideram que a finalidade do estágio é propiciar ao aluno uma aproximação à realidade na qual atuará, adotando uma nova postura, que deve caminhar para a reflexão, a partir da realidade. De acordo com Pimenta e Lima (2005/2006), é necessário que o discente assuma uma posição de professor-investigador para que desenvolva projetos de intervenção para ajudar a desenvolver e escolher metodologias e abordagens para utilizar na prática bem como valorizar e explorar a cultura, o conhecimento e a realidade de seus alunos. É dessa maneira que o docente conseguirá sempre fazer o elo entre teoria e prática. É através da reflexão sobre a prática é que surgem novas possibilidades, novas formas de pensar, novas formas de encarar e agir sobre os problemas. Essa reflexão é indispensável porque é refletindo sobre a prática atual que se pode aperfeiçoar a prática futura (FREIRE, 1996).

Sob esta ótica, o estágio supervisionado é muito mais do que uma exigência acadêmica e constitucional. O estágio nos dá uma oportunidade de crescimento profissional e pessoal, além de exercer o verdadeiro papel de cidadão dentro do contexto social, atuando como um agente multiplicador de conhecimentos e contribuindo com a formação de cidadãos mais participativos e possuidores do espírito crítico (FERNANDEZ; SILVEIRA, 2007).

O estágio é um momento de experiência, sendo muito proveitoso para a futura formação docente. É um espaço onde o futuro docente tem a oportunidade de experiências e práticas que me possibilitam colocar em prática as teorias aprendidas durante a graduação. Aprendendo a desenvolver técnicas e habilidades para enfrentar os problemas do dia-a-dia do ambiente escolar. 
Pimenta (2010) aponta a prática do estágio como uma articulação da formação inicial com a prática profissional, devendo constituir-se em momento de experiências importantes em que o professor pode construir seu reservatório de saberes teóricos e práticos necessários para sua atuação profissional, sendo o estágio um período em que o estagiário poderá se identificar ou não com a profissão relativa ao curso de licenciatura escolhido. Assim:

\begin{abstract}
"O estágio para os professores-alunos que já exercem o magistério tem seu sentido e significado a partir da natureza do trabalho docente, que requer constante revisão das práticas, no sentido de tornar o professor um sujeito que constroem conhecimentos, com capacidade de fazer análise de sua prática fundamentada em um referencial teórico que lhe permita, como resultado, a incessante busca de educação de qualidade e as escolas será sempre o ponto de partida e de chegada aos estágios e nas ações de formação contínua de professores (PIMENTA e LIMA, 2010)".
\end{abstract}

Percebe-se uma relação entre a desqualificação do ensino atual e seu progressivo distanciamento do conhecimento acadêmico, diante das transformações epistemológicas que a Ciência Geográfica vem enfrentando. Cabe desta forma, reduzir esse distanciamento tão problemático, pela imprecisão dos velhos propósitos e das novas formas de crítica, em que o seu sentido tem sido desprezado no ápice da prática social, tornando uma geografia ensinada desprovida de cientificidade (OLIVEIRA, 2010).

O problema permanece na formação do professor e nas condições sociais da escolarização. O mal não está na disciplina ensinada, mas na forma de como é feito este ensino, pois os conhecimentos e noções temáticas da parte dos professores estão abaixo do atual estado da ciência (OLIVEIRA, 2010).

É essencial reforçar dispositivos e práticas de formação de professores baseadas numa investigação que tenha como problemática a ação docente e o trabalho escolar. As propostas teóricas só fazem sentido se forem construídas dentro da profissão, se forem apropriadas a partir de uma reflexão dos professores sobre o seu próprio trabalho (NÓVOA, 2009).

Os lugares da formação podem reforçar a presença pública dos professores, mas, paradoxalmente, também tem se notado a falta dos professores. Há uma ausência dos professores, uma espécie de silêncio de uma profissão que perdeu visibilidade no espaço público. Dessa forma, a força de uma profissão define-se, em grande parte, pela sua capacidade de comunicação com a educação vive um tempo de grandes incertezas e de muitas

Revista de Pesquisa Interdisciplinar, Cajazeiras, n. 2, suplementar, p.420-428, set. de 2017. 
perplexidades. A necessidade, portanto, conduz a uma, que se traduz numa pobreza de práticas. Os textos, as recomendações, os artigos e as teses sucedem-se a um ritmo alucinante repetindo os mesmos conceitos, as mesmas ideias, as mesmas propostas (NÓVOA, 2009).

Um dos grandes perigos dos tempos atuais é uma escola que por um lado é concebida essencialmente como um centro de acolhimento social, para os pobres, com uma forte retórica da cidadania e da participação e por outro lado, uma escola claramente centrada na aprendizagem, e nas tecnologias, destinada a formar os filhos dos ricos (NÓVOA, 2009).

Não basta atribuir responsabilidades às diversas entidades, é necessário que elas tenham uma palavra a dizer, que elas tenham capacidade de decisão sobre os assuntos educativos (NÓVOA, 2009).

É nesta perspectiva que a proposta adquire todo seu sentido, abrindo para a possibilidade de um novo contrato educativo, cuja responsabilidade é partilhada por um conjunto de atores e de instâncias sociais, não ficando apenas nas mãos dos educadores profissionais (NÓVOA, 2009).

Partindo dessas transformações que ocorram ao longo do tempo no ensino, o ensino de geografia na atualidade também vem passando por várias reformulações, diante da reflexão sobre o papel da escola na sociedade e em presença das grandes transformações sócio espaciais que vem ocorrendo.

\footnotetext{
"Não há ensino sem pesquisa e pesquisa sem ensino... No meu entender, o que há de pesquisador no professor não é uma qualidade ou uma forma de ser ou de atuar que se acrescente à de ensinar. Faz parte da natureza da prática docente a indagação, a busca, a pesquisa. Esses que - fazeres se encontram um no corpo do outro. Enquanto ensino, continuo buscando, reprocurando. Ensino porque busco, porque indaguei, porque indago e me indago. Pesquiso para constatar, constatando, intervenho, intervindo educo e me educo. Pesquiso para conhecer o que ainda não conheço e comunicar ou anunciar a novidade (FREIRE, 1996)".
}

Lecionar geografia não é uma tarefa nada fácil, visto que, por muito tempo esta foi tida como uma disciplina descritiva e desinteressante. Partindo dessa perspectiva, convêm ao docente a responsabilidade de desconstruir esse tradicionalismo, que ainda existe no processo educacional. Configurando um dos principais desafios que o docente de geografia tem de enfrentar no cotidiano escolar. 
As dificuldades levantadas pelos "novos alunos" chamam a atenção para a dimensão humana e relacional do ensino, para esse corpo-a-corpo diário a que os professores estão obrigados. Exige que os professores sejam pessoas inteiras, reconhecendo que é necessário a tecnicidade e cientificidade do trabalho docente. E que é fundamental reforçar a pessoaprofessor e o professor-pessoa (NÓVOA, 2009).

É essencial para que cada um adquira uma maior consciência do seu trabalho e da sua identidade como professor. A formação deve contribuir para criar nos futuros professores hábitos de reflexão e de autorreflexão que são essenciais numa profissão que não se esgota em matrizes científicas ou mesmo pedagógicas, e que se define, inevitavelmente, a partir de referências pessoais (NÓVOA, 2009).

Cabe ao professor buscar e desvendar caminhos e alternativas ainda não explorados para a construção de uma nova Geografia que tem como fator principal, propiciar aos estudantes a compreensão de aspectos essenciais do cotidiano e da vida social ao tentar a leitura do espaço e das relações do homem com seu meio (KAERCHER, 2007).

A geografia é uma ciência dinâmica que se constrói por meio das inter-relações da sociedade e da natureza. Desta forma, para a arte de ensinar geografia são necessárias reflexões acerca do que ensinar e de como ensinar.

Vê-se que a Geografia tem repensado o seu papel diante desta sociedade, que passa a exigir da escola uma educação voltada para a formação da cidadania, instrumentalizando o aluno para que esse tenha condições de usar coerentemente o aprendido, processar as ideias e as transformando em conhecimento.

[...] "Como a Geografia é uma ciência que tem relacionamento com uma série de ciências afins, é natural que entre ela e as outras ciências se desenvolvam áreas de conhecimento intermediário, ora como ramos do conhecimento geográfico, ora como ramos do conhecimento de outras ciências que se tornaram ou tendem a tornar-se novas ciências a serem pragmaticamente catalogadas (ANDRADE, 1987)".

Assim os procedimentos metodológicos adotados na regência a todo o momento levou em conta o saber do educando, levando-o à percepção crítica da realidade e principalmente em seu próprio espaço de vivência que deve ser valorizado no processo de ensino e aprendizagem: 


\begin{abstract}
"Os métodos de uma pedagogia crítico-social dos conteúdos não partem, então, de um saber artificial, depositado a partir de fora, nem do saber espontâneo, mas de uma relação direta com a experiência do aluno, confrontada com o saber trazido de fora. $\mathrm{O}$ trabalho docente relaciona a prática vivida pelos alunos com os conteúdos propostos pelo professor, momento em que se dará a "ruptura" em relação à experiência pouco elaborada (LUCKESI, 1994)".
\end{abstract}

Assim, as aulas foram desenvolvidas com a exploração dos conteúdos com o auxílio recursos metodológicos modernos, e também com a realização de atividades dinâmicas que facilitaram a compreensão dos conteúdos.

Todas as etapas desenvolvidas durante o Estágio Supervisionado em Geografia são enriquecedoras, assim como os momentos vividos na sala de aula durante a regência, pois o discente fica frente a frente com a realidade educacional do atual sistema de ensino, enfrentando os problemas, superando suas próprias expectativas ou se decepcionando com as realidades do que o atual ensino moderno concretiza-se, mas, é um momento crucial para pôr em prática as teorias estudadas durante a graduação.

\title{
CONSIDERAÇÕES FINAIS
}

O estágio é um período em que se busca vincular os aspectos teóricos com os aspectos práticos e, sobretudo perceber a necessidade em assumir uma postura não só crítica, mas também reflexiva na prática educativa diante da realidade e para que se possa buscar uma educação de qualidade. Essa fase do estágio supervisionado é essencial para a futura formação docente, onde se tem a oportunidade de ir a campo prático com o objetivo de conhecer e vivenciar a realidade escolar, a partir do que é ensinado nas disciplinas de Estágio Curricular Supervisionado em Geografia, desenvolvendo ações que possam intervir de forma significativa no processo de ensino e de aprendizagem, e que se tenha uma postura de um professor preocupado com a aprendizagem dos alunos e que busque ser o mediador entre o aluno e o conhecimento, pois a educação vive em constante mudança e evolução.

A partir dessa perspectiva, considera-se importante ampliar o debate acerca do ensino de Geografia e da formação docente, no que se refere aos estágios supervisionado. Os professores dentro de suas competências, procuram evoluir suas práticas pedagógicas 
buscando a melhoria do ensino, por outro lado, há um grande número de profissionais que não tem buscado essa melhoria dentro de sua área de conhecimento, e suas fontes não ultrapassam as pesquisas junto aos livros didáticos

É necessário que o aluno desenvolva um olhar crítico, concretizando e alcançando assim os principais objetivos da Geografia, que devem estar pautados na vivência do aluno, que leva para a sala de aula experiências de vida adquiridas fora da escola, as quais, muitas vezes, são ignoradas pelo professor ou pela própria comunidade escolar. Para a viabilização desse propósitos sugerido, é fundamental que o professor esteja motivado para transmitir entusiasmo e interesse aos alunos.

\section{REFERÊNCIAS}

ANDRADE, Manuel Correa. Geografia: ciência sociedade. São Paulo: Atlas, 1987.

BRASIL. Conselho Nacional de Educação. Lei $n^{\circ}$ 9.394, de 20 de dezembro de 1996. Disponível em: http://portal.mec.gov.br/seed/arquivos/pdf/tvescola/leis/lein9394.pdf. Acesso em: 10/09/2016.

FERNANDEZ, C.M.B.; SILVEIRA, D.N. Formação inicial de professores: desafios do estágio curricular supervisionado e territorialidades na licenciatura. In: $30^{\mathrm{a}}$ Reunião Anual da ANPED, 2007, Caxambu. Anais da 30 ${ }^{\mathbf{a}}$ Reunião anual da ANPED. Disponível em: http://30reuniao.anped.org.br/trabalhos/GT04-3529--Int.pdf. Acesso em: 05/06/2017.

FREIRE, P. Pedagogia da autonomia: saberes necessários à prática educativa. Rio de Janeiro: Paz e Terra, 1996.

KAERCHER, Nestor. Práticas geográficas para ler pensar o mundo entender e conversar com o outro e descobrir a si mesmo. In: REGO, Nelson, CASTROGIOVANNI, Antonio C., KAERCHER, Nestor (Orgs.). Práticas pedagógicas para o ensino médio. Porto Alegre: Artmed, 2007.

LUCKESI, Cipriano Carlos. Filosofia da educação. Cortez Editora. São Paulo, 1994.

OLIVEIRA, Christian Dennys Monteiro de. Sentidos da geografia escolar. Fortaleza: Edições UFC, 2010. 228 p. il.; Isbn: 978-85-7282- 356-2 (Coleção Estudos Geográficos, n. $5)$.

NÓVOA, António. Professores: imagens do futuro presente. Lisboa: EDUCA, 2009.

PIMENTA, S. G.; LIMA, M. S. L. Estágio e docência. São Paulo: Cortez, 2004.

PIMENTA, S. G.; LIMA, M. S. L. Estágio e docência: diferentes concepções. RevistaPoíesis. Volume 3, Números 3 e 4, pag.5-24, 2005/2006.

PIMENTA, S.G. O estágio na formação de professores: unidade teoria e prática. 9 ed. São Paulo: Cortez, 2010. 